\title{
SÍNTESE VERDE DE NANOPARTÍCULAS DE COBRE IMPREGNADAS EM CARVÃO ATIVADO PARA REMOÇÃO DE NITRATO DA ÁGUA
}

\author{
C.R.GALAN ${ }^{1 *}$, M.F.SILVA ${ }^{1}$, L. NISHI ${ }^{1}$, R.BERGAMASCO $^{1}$, M. F. VIEIRA ${ }^{1}$ \\ ${ }^{1}$ Universidade Estadual de Maringá, Departamento de Pós-Graduação em Engenharia Química, \\ *e-mail: crislaine_rodriguesgalan@hotmail.com
}

\begin{abstract}
RESUMO
Nanopartículas metálicas apresentam funcionalidades adsorventes, assim como o carvão ativado. Combinando as propriedades de ambos, por meio de impregnação, é possível produzir um material que atenda a uma lista de aplicações para adsorção de contaminantes em água. Existem diferentes metodologias de impregnação, no entanto, estas são caras e utilizam produtos poluentes. Assim, o presente trabalho objetiva o desenvolvimento de um processo de síntese "verde", isto é, ambientalmente correto, para impregnação das nanopartículas de cobre em carvão ativado utilizando extratos de folhas de Moringa oleífera, a fim de remover nitrato da água. Para isso, soluções de cobre com diferentes concentrações foram adicionadas ao carvão ativado juntamente com o extrato de folhas de moringa. Em seguida, foram separados por filtração e secos, sendo caracterizados por BET, MEV, MET e EDS. Foram realizados experimentos de adsorção para avaliar a eficiência de remoção de nitrato da água, sendo as concentrações determinadas por espectrofotometria UV. Os resultados confirmaram a impregnação das nanopartículas metálicas de cobre sobre o carvão e que os mesmos possuem elevada área superficial, apresentando remoção significativa de nitrato após os testes de adsorção. Assim, pode-se concluir que a síntese "verde" para impregnação em carvão ativado foi eficiente e que os materiais produzidos são potenciais adsorventes para remoção de contaminantes da água, como o nitrato.
\end{abstract}

\section{INTRODUÇÃo}

O desenvolvimento de materiais formados por nanopartículas tem crescido constantemente devido sua grande aplicabilidade em diversas áreas, como materiais para área médica, catálise, sensores, filtros, entre outras. Em filtros, nanopartículas metálicas, como prata (JIA, SUN, GU, 2013), ferro (PRASAD et al. 2011) e cobre (KUMAR et al. 2012) tem sido utilizadas, pois apresentam funcionalidade como adsorventes de poluentes, corantes e metais pesados, além de serem eficazes na atividade bactericida. Por apresentar baixa toxidade e custo inferior, principalmente em relação à prata, o cobre tem sido um metal viável para a produção de nanopartículas metálicas.

O carvão ativado, devido sua alta área superficial e estrutura porosa, também possui ótimas propriedades adsorventes e baixo custo, colocando-o como uma importante opção para a eliminação de poluentes orgânicos e inorgânicos da água, filtração, purificação, desodorização e separação (PEREIRA et al. 2014). Assim, combinando as propriedades adsorventes do carvão ativado com as das nanopartículas de cobre metálico é possível produzir um material que atenda a uma extensa lista de aplicações para adsorção de contaminantes em água. 
Para que esta combinação aconteça é necessário realizar a impregnação das nanopartículas metálicas de cobre no carvão ativado. Existem diferentes metodologias para impregnação, destacando-se: co-precipitação, tratamento térmico e redução de íons com agentes redutores químicos. No entanto, estes métodos apresentam custo elevado e envolvem utilização de produtos químicos poluentes (WANG et al. 2013). Mediante isso, tem-se buscado o desenvolvimento de metodologias que minimizem os impactos ambientais, destacando entre estas, a síntese "verde" de nanopartículas.

A síntese "verde" fundamenta-se em princípios limpos, rentáveis e atóxicos, sendo caracterizada por ser simples, de baixo custo e relativamente reprodutível, resultando, muitas vezes, em materiais mais estáveis do que os métodos tradicionais. Para a obtenção de nanopartículas metálicas utilizam agentes redutores naturais, como vitaminas, açúcares, extratos de plantas, polímeros biodegradáveis e microrganismos. Dentre estes, os materiais a base de plantas são os melhores candidatos, pois se acredita que os polifenóis presentes em sua composição sejam a tecla ativa para a síntese (KHARISSOVA et al. 2013).

Pesquisas trazem a utilização de extratos aquosos de Moringa oleífera para a síntese "verde" de nanopartículas metálicas, caracterizando-a como um agente redutor de eficiência significativa, além de destacarem suas diversas propriedades medicinais (ANAND et al. 2015, MUBAYI et al. 2012).

Carvão ativado impregnado com nanopartículas metálicas pode ser utilizado como adsorvente para remoção de nitrato da água (CHO et al. 2011). A ingestão de água com elevadas concentrações deste íon pode resultar em problemas graves para a saúde humana, como meta-hemoglobinemia em crianças e câncer de estômago em adultos (OTA et al. 2013)

Dessa forma, este estudo tem como objetivo o desenvolvimento de um processo de síntese "verde" para impregnação de nanopartículas metálicas de cobre em carvão ativado utilizando extratos de folhas de Moringa oleífera, a fim de remover nitrato da água.

\section{MATERIAIS E MÉTODOS}

Folhas frescas de Moringa oleífera colhidas de uma árvore plantada junto a Universidade Estadual de Maringá (UEM) foram utilizadas para a preparação do extrato em uma concentração de $60 \mathrm{~g} / \mathrm{l}$, conforme descrito por Wang et al. (2014).

Foram empregadas concentrações de cobre a $0,5 \%, 1 \%$ e $1,5 \%$ relacionadas à massa de carvão ativado. As quantidades necessárias de sulfato de cobre $\left(\mathrm{CuSO}_{4} 5 \mathrm{H}_{2} \mathrm{O}\right.$ PA marca Anidrol) foram solubilizadas em água destilada e adicionadas ao carvão ativado granular de casca de coco de dendê juntamente com o extrato de folhas de moringa em proporção de 2:1 (WANG et al. 2014). Em seguida, os carvões foram levados para agitação em Shaker (TE421 TECNAL) por 36 horas, sendo, posteriormente separados por filtração e secos em estufa (SXCR/42 STERILIFER) a $50^{\circ} \mathrm{C}$.

Realizada a impregnação, os materiais obtidos foram caracterizados por meio da Determinação de Área Superficial e Volume de Poros por BET (aparelho Quanta Chrome Nova 1000 series), Microscopia Eletrônica de Varredura (SHIMADZU SS-550 SUPERSCAN), Microscopia Eletrônica de Transmissão (JEOL JEM-1400 com voltagem de aceleração de $120 \mathrm{kV}$ ) e Espectroscopia de raios-X por energia dispersiva.

Para avaliar a remoção de nitrato $\left(\mathrm{NaNO}_{3}\right.$ PA marca Anidrol) com os carvões impregnados e com o carvão ativado puro, foram realizados ensaios de adsorção, seguindo a metodologia descrita por Öztürk e Bektas (2004) e Ota et al. (2013). As concentrações de nitrato foram determinadas por espectrofotometria UV (UV-VIS HACH 
DR 5000) conforme proposto em IAL (2004). Todos os experimentos foram realizados em duplicata e a porcentagem de nitrato adsorvido foi calculada pela Equação 1:

$\%=\frac{C o-C e}{C e} * 100$

onde $C o$ é a concentração inicial de nitrato e $C e$ a concentração de equilíbrio.

\section{RESULTADOS E DISCUSSÕES}

Após o processo de impregnação, foram obtidas três amostras de carvões, as quais estão identificadas na Tabela 1.

Tabela 1 - Identificação das amostras de carvão impregnado com nanopartículas

\begin{tabular}{cc}
\hline Amostra & $\mathrm{Cu}(\%)$ \\
\hline 1 & 1,5 \\
2 & 1,0 \\
3 & 0,5
\end{tabular}

Fonte: Autor (2015)

\subsection{Caracterização}

Para melhor embasamento da discussão dos resultados, serão apresentados juntamente com as amostras de carvões impregnados, os resultados da caracterização do carvão ativado puro.

\subsection{1 Área Superficial e Volume de Poros}

A caracterização textural dos carvões, tanto do puro, quanto dos impregnados estão apresentados na Tabela 2. Os parâmetros analisados foram área superficial BET, área de microporos (método $\mathrm{t}$ ), volume de microporos (método HK) e o diâmetro de poros.
Tabela 2 - Parâmetros Caracterização Textural

\begin{tabular}{ccccc}
\hline Amostra & $\begin{array}{c}\mathrm{S}_{\mathrm{BET}} \\
\left(\mathrm{m}^{2} / \mathrm{g}\right)\end{array}$ & $\begin{array}{c}\mathrm{S}_{\text {Micro }} \\
\left(\mathrm{m}^{2} / \mathrm{g}\right)\end{array}$ & $\begin{array}{c}\mathrm{V}_{\text {Micro }} \\
\left(\mathrm{m}^{3} / \mathrm{g}\right)\end{array}$ & $\begin{array}{c}\mathrm{D}_{\mathrm{p}} \\
(\hat{\mathrm{A}})\end{array}$ \\
\hline Puro & 575,3 & 416,5 & 0,2368 & 11,94 \\
1 & 636,7 & 375,7 & 0,1663 & 10,20 \\
2 & 640,3 & 375,4 & 0,1647 & 9,79 \\
3 & 559,4 & 348,8 & 0,1566 & 10,27
\end{tabular}

Fonte: Autor (2015)

Pode-se observar que tanto o carvão puro quanto os impregnados apresentam elevada área superficial $\left(\mathrm{S}_{\mathrm{BET}}\right)$, evidenciando suas potencialidades como adsorventes. Nas amostras 1 e 2, impregnadas com maiores concentrações de cobre $(1,5 \%$ e $1,0 \%)$, verificou-se um aumento da área superficial. Segundo Yin et al. (2007) e Demiral et al. (2010) esta elevação da área superficial pode estar relacionada ao processo de impregnação, uma vez que este otimiza as propriedades existentes do carvão ativado.

Já a área de microporos $\left(\mathrm{S}_{\text {micro }}\right)$, o volume de microporos $\left(\mathrm{V}_{\text {micro }}\right)$ e o diâmetro de poros $\left(\mathrm{D}_{\mathrm{p}}\right)$ diminuíram após a impregnação das nanopartículas de cobre. De acordo com Darezereshki et al. (2013) esta redução pode ocorrer devido a formação de nanopartículas no interior dos poros.

\subsubsection{Microscopia Eletrônica de Varredura}

As micrografias obtidas por MEV das amostras de carvão ativado impregnado e puro são mostradas na Figura 1. Pode-se observar que as superfícies de todas apresentam estrutura porosa. No entanto, nas amostras 1, 2 e 3 percebem-se partículas menores depositadas sobre a matriz do carvão, possivelmente devido à presença de nanopartículas de cobre provenientes do processo de impregnação. 
Figura 1 - MEV das amostras de carvão ativado puro e impregnado
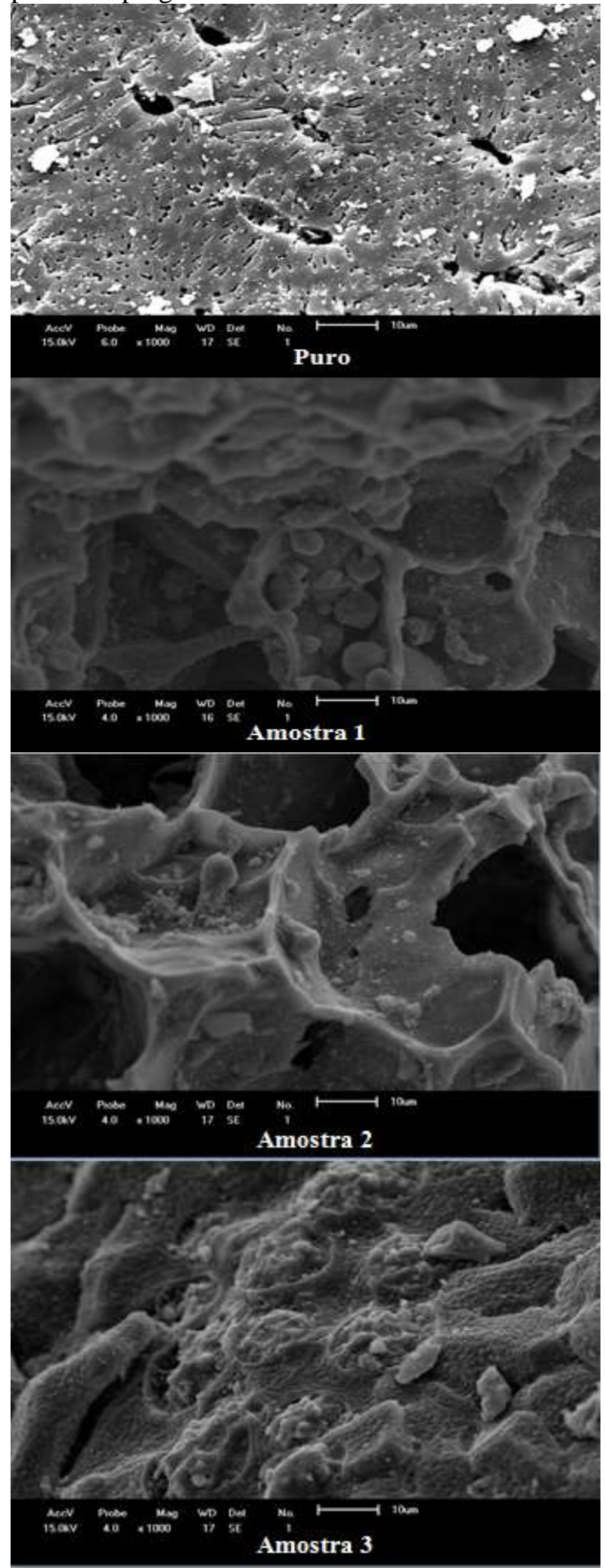

Fonte: Autor (2015)

\subsubsection{Microscopia Eletrônica de Transmissão}

Nas imagens de MET apresentadas na Figura 2 estão identificadas as nanopartículas de cobre formadas. Verifica-se nas três amostras impregnadas, a matriz carbonácea de coloração acinzentada com partículas e aglomerados de partículas de coloração mais escura, características de partículas metálicas, neste caso, nanopartículas de cobre. Também é possível verificar que as partículas apresentam tamanho inferior a $100 \mathrm{~nm}$, como pode ser observado comparando com a barra de escala, indicando que o método da redução de cobre utilizando extrato de moringa é eficiente na obtenção de nanopartículas.

Figura 2 - MET das amostras de carvão ativado impregnado

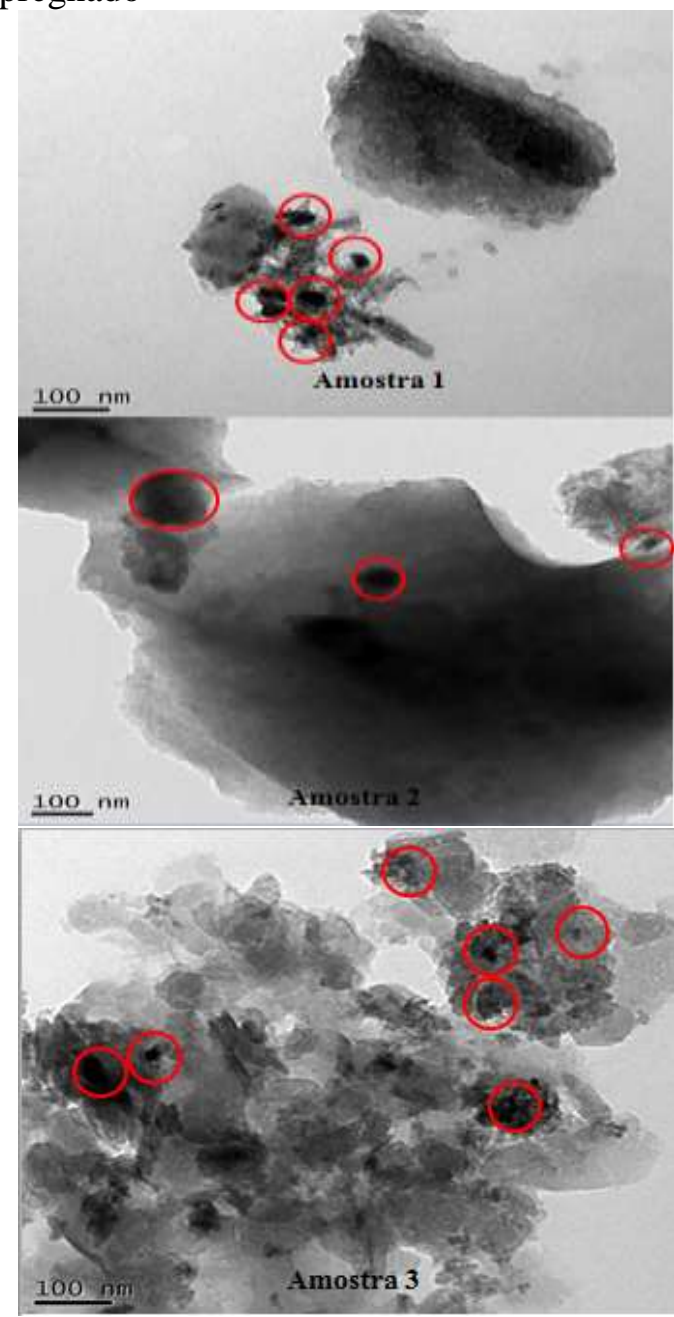

Fonte: Autor (2015) 
3.1.4 Espectroscopia de raios-X por energia dispersiva

Por meio do espectro de EDS, como apresentado na Figura 3, pode-se observar a composição elementar do carvão ativado puro, com a presença dos picos de ouro (devido ao recobrimento efetuado para realização da análise), bem como carbono, oxigênio e alguns metais como $\mathrm{Al}, \mathrm{Mg}$ e $\mathrm{Si}$, encontrados em biomassa. Já nas amostras 1, 2 e 3, além dos elementos encontrados no carvão puro, verificaram-se picos de $\mathrm{Cu}$, indicando a impregnação das nanopartículas deste metal no carvão.

Figura 3 - EDS das amostras de carvão ativado puro e impregnado
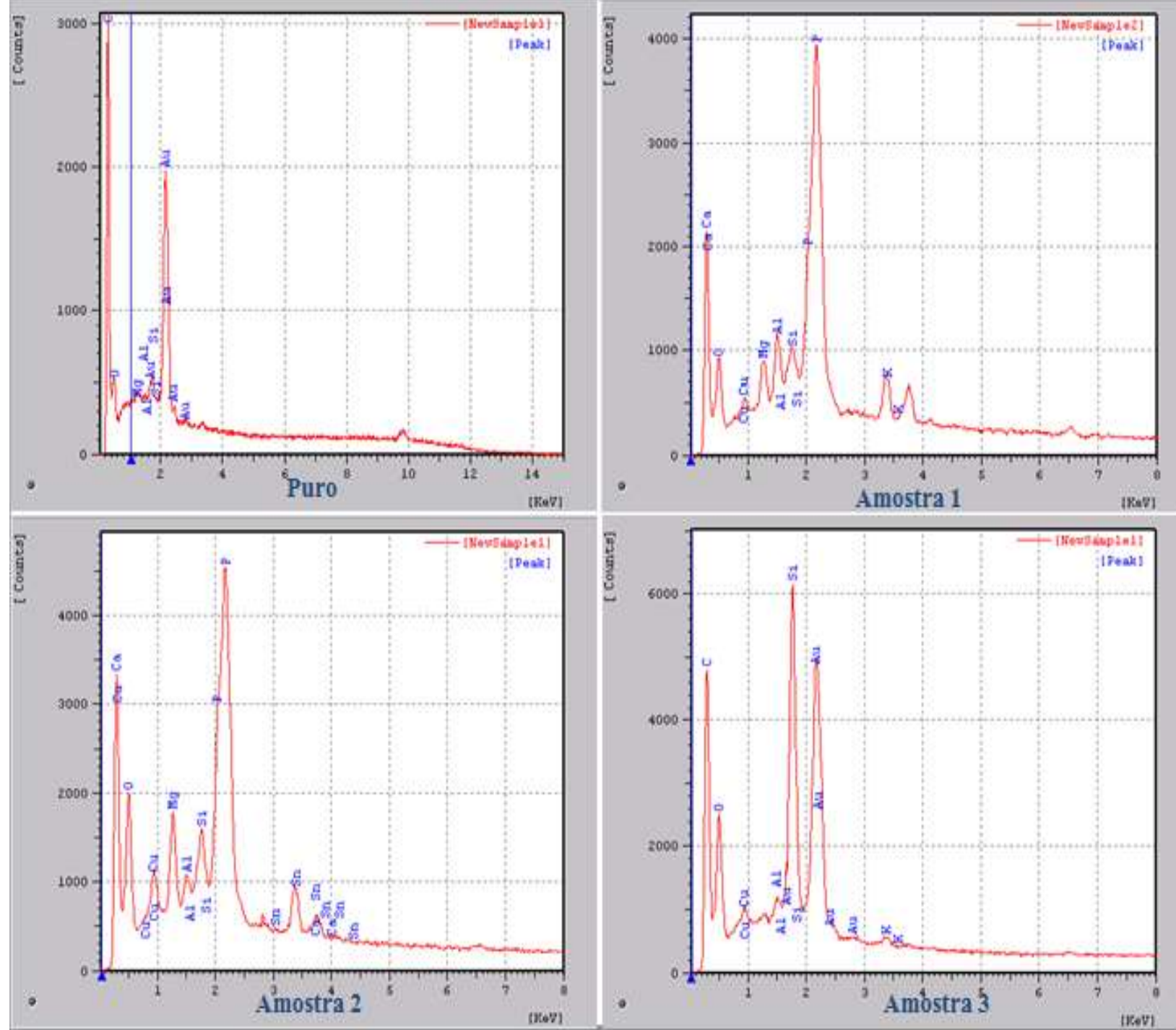

Fonte: Autor (2015)

\subsection{Adsorção}

A Figura 4 apresenta os resultados obtidos com os ensaios de adsorção utilizando como adsorventes o carvão ativado puro e os carvões impregnados com nanopartículas de cobre. Através dos valores obtidos em duplicata com um desvio de $\pm 2 \%$, pode-se observar que os carvões impregnados apresentaram valores de remoção superiores quando comparado ao valor obtido com o carvão ativado puro. 
Figura 4 - \% Remoção de nitrato utilizando carvões impregnados e carvão ativado puro

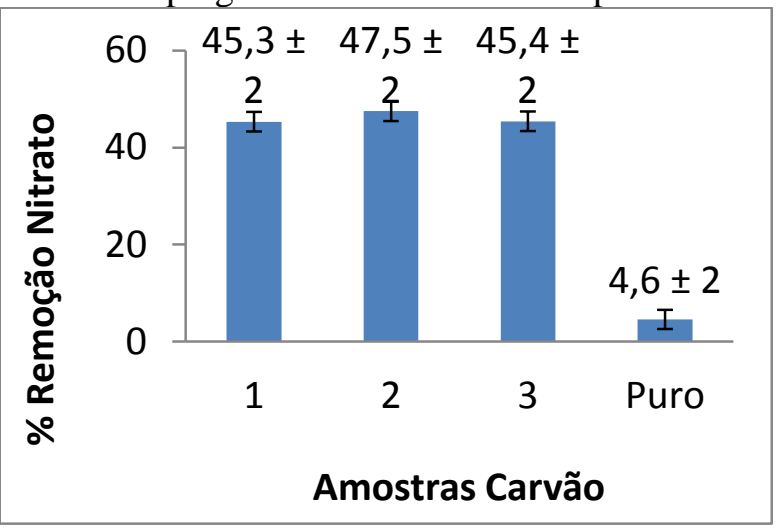

Fonte: Autor (2015)

\section{CONSIDERAÇÕES FINAIS}

Pode-se concluir que o processo de impregnação de nanopartículas metálicas de cobre por meio de síntese "verde" utilizando como agente redutor natural extratos de folha Moringa oleífera foi eficiente, indicando dessa forma a possibilidade de redução de uso de solventes tóxicos para a obtenção dos carvões impregnados.

Os carvões impregnados apresentaram remoção de nitrato superior (valores acima de $40 \%$ ) quando comparados com a remoção obtida utilizando o carvão puro, cujo valor encontrado, considerando o desvio, é de no máximo 6\%. Assim, os carvões impregnados com nanopartículas de cobre podem ser empregados como adsorventes eficientes no tratamento de água.

\section{NOMENCLATURA}

BET - Brunauer, Emmet e Teller

EDS - Espectroscopia de raios-X por energia dispersiva

Varredura

MEV - Microscopia Eletrônica de

MET - Microscopia Eletrônica de Transmissão

\section{REFERÊNCIAS}

ANAND, K., GENGAN, R. M., PHULUKDAREE, A., CHUTURGOON, A. Agroforestry waste Moringa oleifera petals mediated green synthesis of gold nanoparticles and their anti-cancer and catalytic activity. Journal of Industrial and Engineering Chemistry, v. 21 p. 1105-1111, 2015.

CHO, D. W., CHON, C.M., KIM, Y., JEON, B. H., SCHWARTZ, F. W., LEE, E.S., SONG, $\mathrm{H}$. Adsorption of nitrate and $\mathrm{Cr}$ (VI) by cationic polymer-modified granular activated carbono. Chemical Engineering Journal, v. 175, p. 298-305, 2011.

DAREZERESHKI, E., BAKHTIARI, F., VAKYLABAD, A.B., HASSANI, Z., Singlestep synthesis of activated carbon $/ \gamma-\mathrm{Fe} 2 \mathrm{O} 3$ nano-composite at room temperature. Materials Science in Semiconductor Processing, v.16, p.221-225, 2013.

DEMIRAL, H., GÜNDÜZ, G. Removal of nitrate from aqueous solutions by activated carbon prepared from sugar beet bagasse. Bioresource Technology, v. 101, p.16751680, 2010.

IAL-INSTITUTO ALDOFO LUTZ. Métodos físico-químicos para análise de alimentos. 4. ed. São Paulo, 2004.

JIA, Z., SUN, H., GU, Q. Preparation of Ag nanoparticles with triethanolamine as reducing agent and their antibacterial property. Colloids and Surfaces A: Physicochemical and Engineering Aspects, v. 419, p. 174-179, 2013.

KHARISSOVA, O.V., DIAS, H.V., KHARISOV, B., PEREZ, B.O., JIMENEZ, V.P.,The greener synthesis of nanoparticles. Trends in Biotechnology, v. 31, p. 240-248, 2013. 
KUMAR, A. C., KUMAR, R. S., PRASUN, A. C., PULAKESH, A., RUCHIRA, C., TARAKDAS, B., A simple robust method for synthesis of metallic copper nanoparticles of high antibacterial potency against E. coli. Nanotechnology, v. 23, p. 85-103, 2012.

MUBAYI, A., CHATTERJI, S., RAI, P.M., WATAL, G. Evidence based green synthesis of nanoparticles. Advanced Materials Letters, v. 3, p. 519-525, 2012.

OTA, K., AMANO, Y., AIKAWA, M., MACHIDA, M. Removal of nitrate ions from water by activated carbons (ACs) - Influence of surface chemistry of ACs and coexisting chloride and sulfate ions. Applied Surface Science, v. 276, p. 838- 842, 2013.

ÖZTÜRK, N., BEKTAS, T. E. Nitrate removal from aqueous solution by adsorption onto various materials. Journal of Hazardous Materials, B112, p.155-162, 2004.

PEREIRA, R. G., VELOSO, C. M., SILVA, N. M., SOUSA, L.F., BONOMO, R.C.F., SOUZA, M.O.G., FONTAN, R. C. Preparation of activated carbons from cocoa shells and siriguela seeds using $\mathrm{H} 3 \mathrm{PO} 4$ and $\mathrm{ZnCL} 2$ as activating agents for BSA and $\alpha$-lactalbumin adsorption. Fuel Processing Technology, v. 126, p. 476-486, 2014.

PRASAD, B., GHOSH, C., CHAKRABORTY, A., BANDYOPADHYAY, N., RAY, R.K., Adsorption of arsenite (As3+) on nano-sized $\mathrm{Fe}_{2} \mathrm{O}_{3}$ waste powder from the steel industry. Desalination, v. 274, p. 105-112, 2011.

WANG, T., JIAJIANG, L., CHEN, Z., MEGHARAJ, M., NAIDU, R. Green synthesized iron nanoparticles by green tea and eucalyptusleaves extracts used for removal of nitrate in aqueous solution. Journal of Cleaner Production, p. 1-7, 2014.
WANG, T., SU, J., JIN, X., CHEN, Z. MEGHARAJ, M. NAIDU, R. Functional clay supported bimetallic nZVI/Pd nanoparticles used for removal of methyl orange from aqueous solution. Journal of Hazardous Materials, v. 262, p. 819-825, 2013.

YIN, C.Y., AROUA, M.K., DAUD, W.M.A.W. Review of modifications of activated carbon for enhancing contaminant uptakes from aqueous solutions. Separation and Purification Technology, v. 52, p.403415, 2007.

\section{AGRADECIMENTOS}

A CAPES pelo apoio financeiro concedido a este projeto. 